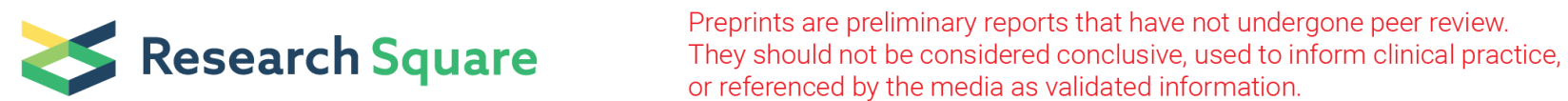

\section{An 'Intermetallic' Molecular Nanomagnet with the Lanthanide Coordinated Only by Transition Metals}

\section{Michał Magott}

Jagiellonian University https://orcid.org/0000-0002-4566-2636

\section{Maria Brzozowska}

Jagiellonian University

\section{Stanisław Baran}

Jagiellonian University https://orcid.org/0000-0003-1819-5603

\section{Veacheslav Vieru}

Maastricht University https://orcid.org/0000-0001-6375-4537

Dawid Pinkowicz ( $\sim$ dawid.pinkowicz@uj.edu.pl)

Jagiellonian University

\section{Article}

Keywords: Lanthanide complexes, lanthanide-transition metal bonds, organometallic chemistry, molecular magnetism, single molecule magnet, molecular nanomagnet, magnetic memory

Posted Date: January 18th, 2022

DOI: https://doi.org/10.21203/rs.3.rs-1264873/v1

License: (c) (i) This work is licensed under a Creative Commons Attribution 4.0 International License. Read Full License

Version of Record: A version of this preprint was published at Nature Communications on April 19th, 2022. See the published version at https://doi.org/10.1038/s41467-022-29624-7. 


\section{Abstract}

Magnetic molecules known as molecular nanomagnets (MNMs; or single molecule magnets SMMs) may be the key to ultra-high density data storage. A single sub-nanometer MNM is capable of storing a single bit of information while being 2-3 orders of magnitude smaller than the magnetic domains in the current HDD technology. The best performing molecular nanomagnets are designed by carefully arranging $p$ element donor atoms ( $\mathrm{C}, \mathrm{N}$ or $\mathrm{O})$ around the central magnetic ion. This strategy, however, seems to be reaching its limit as the magnetic memory effect disappears above $80 \mathrm{~K}$ for this class of compounds. Inspired by the structure of the hardest intermetallic magnet $\mathrm{SmCo}_{5}$, we have synthesized a nanomagnetic molecule where the central lanthanide $(\mathrm{Ln})$ ion $\mathrm{Er} \mathrm{rll}^{\mathrm{Il}}$ is coordinated solely by three transition metal (TM) ions in a perfectly trigonal planar fashion. The molecule $\left[\mathrm{Er}^{\prime \prime \prime}\left(\operatorname{Re}^{\prime} \mathrm{Cp}_{2}\right)_{3}\right]\left(\mathrm{ErRe}_{3}\right)$ constitutes the first example of a molecular nanomagnet (MNM; or single molecule magnet SMM) with unsupported LnTM bonds and paves the way towards molecular intermetallics with strong direct magnetic exchange interactions. Such interactions are believed to be crucial for quenching the quantum tunneling of magnetization which limits the application of Ln-SMMs as sub-nanometer magnetic memory units.

\section{Introduction}

Rare-earth intermetallic magnets - samarium-cobalt $(\mathrm{SmCo})^{1}$ and neodymium $(\mathrm{NdFeB})^{2,3}$ - are the strongest permanent magnets known to date with multiple applications in modern technology ranging from hard disk drives to electric vehicles and wind turbines. ${ }^{4}$ Their commercial success results from the combination of the strong magnetic anisotropy of rare earths and their direct magnetic coupling with transition metal ions. At the other far end of the current search for novel magnetic materials are magnetic molecules, called molecular nanomagnets ${ }^{5}$ (MNMs) or single molecule magnets (SMMs). MNMs are molecule-sized objects with magnetic memory effects governed by quantum mechanics. ${ }^{6-10}$ They are strongly believed to revolutionize magnetic information storage, but at the moment do not have any realworld applications, as their performance is limited by low blocking temperatures and quantum tunneling of magnetization (QTM). ${ }^{11}$ Current trends in the design of MNMs ${ }^{12,13}$ were ignited by the discovery of terbium double-decker $\left[\mathrm{TbPc}_{2}\right]^{-}(\mathrm{Pc}=\text { phthalocyanine dianion })^{14}$ and were fueled by the seminal perspective of Rinehart and Long. ${ }^{15}$ Design principles focus on the precise control of the coordination sphere of a single lanthanide center in order to maximize the easy-axis magnetic anisotropy of the complex and to limit the spin-lattice relaxation rates. ${ }^{16-19}$ While this approach led to several breakthroughs, including the observation of the magnetic hysteresis loop of molecular origin above the liquid nitrogen barrier for dysprosocenium ${ }^{6,7}$ and magnetic field control of the magnetization blocking barrier, ${ }^{20}$ it appears to be reaching its limit as the proposed modifications were not as successful as expected. ${ }^{21,22}$

The original approach to MNMs was based on designing multinuclear systems with strong magnetic superexchange, where several paramagnetic centers are "glued" together by bridging ligands to form a 
high-spin molecule. If magnetic anisotropy is present in such a system, it shows MNM properties. ${ }^{23,24} \mathrm{An}$ MNM of this type stands behind the success story of the whole field as it was indeed started by the discovery of a dodecanuclear carboxylate-bridged cluster $\mathrm{Mn}_{12}-$ a high-spin molecule $(S=10)$ comprising eight $\mathrm{Mn}^{\mathrm{III}}$ and four $\mathrm{Mn}^{\mathrm{IV}}$ ions interacting magnetically via the bridging carboxylate ligands. ${ }^{25-27}$ However, the indirect character of these magnetic interactions, based on weak superexchange coupling mechanism, limits the performance of $\mathrm{Mn}_{12}$ to very low temperatures, below the boiling point of liquid helium. Attempts to adapt this particular strategy to dysprosocenium complexes suffer from a similar problem - weak superexchange interactions of the lanthanides with other metal centers through diamagnetic bridging ligands limit their influence on the slow magnetic relaxation. ${ }^{28-30}$ Therefore, the route towards the high-performance MNMs based on superexchange interactions has been largely abandoned.

Overall, despite the huge progress in the field initiated by $\mathrm{Mn}_{12}$, its ultimate goal - the room-temperature molecular nanomagnet (RT-MNM) - remains elusive. However, the aforementioned examples of the rareearth intermetallics: $\mathrm{SmCO}_{5}{ }^{1}$ and $\mathrm{Nd}_{2} \mathrm{Fe}_{14} \mathrm{~B}^{2}$ provide clues for the possible direction in the design of RTMNMs. Focusing the efforts on molecules comprising a rare-earth metal center coordinated solely by transition metal ions, ${ }^{31-34}$ mimicking the first coordination sphere of the $\mathrm{Sm}$ center in the $\mathrm{SmCo}_{5}$ magnet (Figure 1A-1C) could enable the appearance of the direct exchange coupling between the highly anisotropic lanthanide central ion and the coordinated transition metals. This approach was recently predicted to efficiently suppress QTM in $\mathrm{MNMs}^{35}$ and demonstrated for the ultra-hard MNM $\left(\mathrm{CpiPr}_{5}\right)_{2} \mathrm{Dy}_{2} \mathrm{l}_{3}$ where direct $f-f$ exchange is operational. ${ }^{36}$ Interestingly, even much weaker indirect interactions were reported to be quite efficient in this matter. ${ }^{37}$

The concept of unsupported bonds between the lanthanide and the transition metal was first introduced and explored by Kempe et al. ${ }^{32,34}$ Later, it was proposed by Rinehart and Long ${ }^{15}$ as a possible strategy towards molecular nanomagnets and put to use by Nippe et al. reporting MNMs with unsupported direct bonds between the dysprosium ion and $4 d(\mathrm{Fe})$ or $4 d(\mathrm{Ru})$ transition metal ions. ${ }^{38}$ However, the magnetic memory effect (magnetic hysteresis) has not been observed, most probably due to the unfavorable ligand field geometry ${ }^{38}$ or the unfortunate choice of the rare-earth metal. ${ }^{32}$ Noteworthy, the introduction of $p$ block heavy metals directly into the coordination sphere of the lanthanide was also pursued resulting in interesting examples of MNMs. ${ }^{39,40}$

Here, we apply the principles of easy-axis magnetic anisotropy design with the methodology of Kempe et al. that led previously to rare-earth metal complexes coordinated solely by transition metals. ${ }^{32}$ Herein, we demonstrate the first step toward molecular "intermetallic" nanomagnets, a perfectly trigonal planar $\left[\mathrm{Er}^{\prime \prime \prime}\left(\operatorname{Re}^{\prime} \mathrm{Cp}_{2}\right)_{3}\right]$ complex $\left(\mathrm{ErRe}_{3} ; \mathrm{Cp}=\right.$ cyclopentadienyl anion) with magnetic hysteresis up to $7.2 \mathrm{~K}$ (at 22 Oe/s magnetic sweep rate) where $\mathrm{Er}^{\mathrm{Ill}}$ is solely coordinated by three $\mathrm{Re}^{\mathrm{l}}$ ions.

\section{Results And Discussion}




\section{Synthetic strategy}

$\mathrm{ErRe}_{3}$ is obtained following the literature procedure for $\left[\mathrm{Sm}^{\mathrm{III}}\left(\operatorname{Re}^{\mathrm{l}} \mathrm{Cp}_{2}\right)_{3}\right]$. $^{32}$ The starting material $\left[\mathrm{Er}^{\text {III }}(\mathrm{btmsm})_{3}\right]$ (obtained according to literature procedures ${ }^{41} 42$; btmsm = bis(trimethylsilyl)methyl anion) reacts with $\left[\mathrm{Cp}_{2} \mathrm{ReH}\right]^{43}$ in benzene (Figure 1D). The btmsm ${ }^{-}$ligand coordinated to $\mathrm{Er}^{\mathrm{Ill}}$ acts as a strong base capable of deprotonating $\left[\mathrm{Cp}_{2} \mathrm{ReH}\right]$ - a weak acid. Deprotonation of $\left[\mathrm{Cp}_{2} \mathrm{ReH}\right]$ leads to the elimination of the by-product bis(trimethylsilyl)methane ('alkane elimination' ${ }^{34}$ ) and the formation of the anionic $\left[\mathrm{Cp}_{2} \mathrm{Re}^{l}\right]^{-}$species that readily coordinate to $\mathrm{Er}{ }^{\mathrm{Ill}}$ resulting in the formation of a trigonal planar complex $\left[\operatorname{Er}^{\prime \prime \prime}\left(\operatorname{Re}^{\prime} \mathrm{Cp}_{2}\right)_{3}\right]$.

\section{Crystal structure}

$\mathrm{ErRe}_{3}$ crystallizes slowly from benzene in the form of small yellow prism crystals which were characterized structurally by single-crystal X-ray diffraction (SCXRD; trigonal $R-3$; Table S1). The SCXRD structural analysis confirmed the coordination of three $\mathrm{Re}^{\mathrm{l}}$ ions to the $\mathrm{Er}^{\mathrm{Ill}}$ center with the formation of a nearly perfect trigonal planar neutral complex $\left[\mathrm{Er}^{\mathrm{III}}\left(\mathrm{Re}^{\mathrm{l}} \mathrm{Cp}_{2}\right)_{3}\right]$ (Figure 1C) with the Re-Er-Re angles very close to $120^{\circ}\left(121.22(2), 119.15(2)\right.$ and $\left.119.62(2)^{\circ}\right)$ and the Er atom lying only 0.013(1) $\AA$ above the $\operatorname{Re}_{3}$ plane. The cyclopentadienyl ligands are coordinated solely to $\mathrm{Re}^{\mathrm{l}}$ and arranged in a slightly tilted manner below and above the equatorial plane of the $\mathrm{ErRe}_{3}$ molecule (Figure 1C). There are no other coordination bonds to $\mathrm{Er}{ }^{\prime \prime \prime}$. Other intramolecular contacts of $\mathrm{Er}{ }^{\prime \prime \prime}$ involve $\mathrm{Cp}$ ligands with the shortest $\mathrm{Er} \times \times \times \mathrm{C}$ distances in the 2.829(8)-3.056(13) A range - well beyond typical coordination bonds of lanthanide complexes. The Er-Re distances in $\operatorname{ErRe}_{3}$ (2.9004(5), 2.9124(5) and 2.9172(5) $\AA$ ) are similar to those reported for $\left[\mathrm{Sm}^{\prime \prime \prime}\left(\mathrm{Re}^{\mathrm{l}} \mathrm{Cp}_{2}\right)_{3}\right],\left[\mathrm{La}^{\prime \prime \prime}\left(\mathrm{Re}^{\mathrm{l}} \mathrm{Cp}_{2}\right)_{3}\right]$ and $\left[\mathrm{Lu}^{\mathrm{III}}\left(\mathrm{Re}^{\mathrm{l}} \mathrm{Cp}_{2}\right)_{3}\right]^{32}$ as well as other molecular compounds with unsupported rare earth - transition metal bonds ${ }^{34,38}$ and the intermetallic $\mathrm{SmCo}_{5}$ with Sm-Co distances of $2.888 \AA .^{1}{ }^{1}$ The comparison of the Re-Cp distances in ErRe $\mathbf{E}_{3}$ and the $\left[\mathrm{Cp}_{2} \mathrm{ReH}\right]$ starting material (SCXRD structural analysis of [ $\left.\mathrm{Cp}_{2} \mathrm{ReH}\right]$ was performed as part of this study Table S1; CCDC 2027573) confirms the change of the valence state of the Re centers upon coordination to $\mathrm{Er}^{\mathrm{III}}$. The slightly unsymmetrical and tilted $\left[\mathrm{Cp}_{2} \mathrm{ReH}\right]$ with the average Re-Cp $\mathrm{p}_{\text {centroid }}$ distance of $1.877(44) \AA$ is similar to other compounds of this type ${ }^{44-46}$ and shows slight shortening of these contacts in ErRe 3 to av. 1.864(8) $\AA$ (Figure S1). The $\left[\mathrm{Er}^{\prime \prime \prime}\left(\operatorname{Re}^{\prime} \mathrm{Cp}_{2}\right)_{3}\right]$ molecules are stacked on top of each other in a hexagonal fashion along the $c$ crystallographic direction, leading to the formation of channels filled with disordered benzene molecules (Figure S2). The shortest intermolecular distances between the Er III centers can be found within the aforementioned stacks and amount to 7.6318(6) $\AA$. There are six more nearest $E r^{\text {Ill }}$ neighbors within the $10 \AA$ radius with distances larger than $9 \AA$ (Figure S3). This ensures sufficient magnetic isolation of the individual $\left[\mathrm{Er}^{\prime \prime \prime}\left(\mathrm{Re}^{\mathrm{l}} \mathrm{Cp}_{2}\right)_{3}\right]$ molecules taking into account that all intermolecular contacts are van der Waals in nature and do not transmit magnetic interactions efficiently. Before attempting the magnetic characterization $\mathrm{ErRe}_{3}$ was subjected to a rigorous purity verification by performing powder $\mathrm{X}$-ray diffraction (PXRD) experiment for a sample loaded into a $0.3 \mathrm{~mm}$ glass capillary immersed in benzene 
and sealed using high vacuum grease (identical conditions were applied during the magnetic measurements discussed below). The experimental PXRD pattern shows very narrow peaks and matches almost perfectly the simulated one using $270 \mathrm{~K}$ SCXRD data (Figure S4).

\section{Magnetic properties}

The unusual coordination environment of $\mathrm{Er}^{\mathrm{III}}$ in $\mathrm{ErRe}_{3}$ may cast doubts on the nature of its electronic ground state. However, magnetic measurements for $\mathrm{ErRe}_{3}$ confirm the valence states of the central $\mathrm{Er}^{\mathrm{III}}$ ion and the $\mathrm{Re}^{\mathrm{l}}$ donor atoms. The $\chi T$ ( $\chi$ - molar magnetic susceptibility) value of 11.3

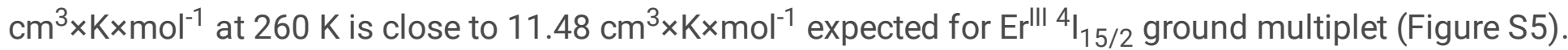
Similar agreement between the experiment and the expected $\chi T$ was reported for $\left[\mathrm{Sm}^{\text {III }}\left(\operatorname{Re}^{\mathrm{l}} \mathrm{Cp}_{2}\right)_{3}\right]\left({ }^{6} \mathrm{H}_{5 / 2}\right.$ multiplet). ${ }^{32}$ This is further confirmed by a very good agreement of the experimental $\chi T$ and the ab initio calculations (red solid line in Figure S5 and supplemental information) using Molcas. ${ }^{47,48}$ The $\chi T(T)$ dependence shows an abrupt increase below $18 \mathrm{~K}$, which can be ascribed to ferromagnetic intermolecular interactions and blocking of magnetization.

The $M(H)(M-$ molar magnetization, $H$ - magnetic field) measurements (magnetic field sweep rate of 2.2 $\mathrm{mT} \times \mathrm{s}^{-1}$ ) revealed the presence of waist-restricted (pinched) magnetic hysteresis loops up to $7.2 \mathrm{~K}$ (Figure $2 \mathrm{~A})$, originating from the slow relaxation of the magnetization of the trigonal $\mathrm{ErRe}_{3}$. This temperature matches $\mathrm{Er}^{\mathrm{III}}$ sandwich and metallocene complexes. ${ }^{49}$ Furthermore, the hysteresis loop in $\mathrm{ErRe}_{3}$ opens in the $0.05-1.5 \mathrm{~T}$ range at $1.8 \mathrm{~K}$ and is the widest among trigonal $\mathrm{Er}{ }^{\mathrm{Ill}} \mathrm{MNMs}$.

The slow magnetization dynamics were studied and confirmed by the alternating current (AC) magnetic susceptibility measurements performed in the $1-10000 \mathrm{~Hz}$ frequency range up to $27 \mathrm{~K}$ in the absence of the external magnetic field (Figure 2C and Table S2). However, the resulting temperature dependence of the magnetic relaxation rate $t^{-1}(T)$ (Figure 2D) contains contributions from three processes: quantum tunneling of magnetization (QTM), Raman and Orbach described by five parameters included in Equation 1:

$\tau^{-1}=A+C T^{n}+\tau_{0}^{-1} \exp \left(\frac{-U_{e f f}}{k_{B} T}\right) \quad$ Eq. 1

hence, all relevant parameters: $A, C, n, t_{0}$ and, most importantly, the effective energy barrier for the magnetization reversal arising from the Orbach relaxation can be extracted only with limited confidence from AC data collected at zero DC field (best fit parameters $A=179(4) \mathrm{s}^{-1}, C=0.137(9) \mathrm{K}^{-\mathrm{n}} \times \mathrm{s}^{-1}, n=$ $3.60(2), \tau_{0}=8.3(8) \cdot 10^{-10} \mathrm{~s}$ and $U_{\text {eff }}=285(3) \mathrm{K}$ with $R^{2}=0.99994$; Figure $\left.2 \mathrm{D}\right)$. To mitigate this issue, the AC magnetic studies were repeated under an applied DC magnetic field of $0.15 \mathrm{~T}$ (Figure S6 and Table S3). The presence of a small applied magnetic field quenches the QTM with only negligible direct process, which was accurately determined from the magnetic field dependence of the relaxation time (Figure S7 
and Table S4). Thus, the temperature dependence of the relaxation rate under $H_{\mathrm{DC}}=0.15 \mathrm{~T}$ could be reliably fitted including only the Raman and Orbach relaxation mechanisms using Equation 2:

$$
\tau^{-1}=C T^{n}+\tau_{0}^{-1} \exp \left(\frac{-U_{e f f}}{k_{B} T}\right) \quad \text { Eq. } 2
$$

where $\tau^{-1}$ is the magnetic relaxation rate, $C$ and $n$ parameters describe the Raman-like process, and $\tau_{0}$ and $U_{\text {eff }}$ are related to the Orbach process. The satisfactory fit could be obtained with $C=0.0035(4) \mathrm{K}^{-\mathrm{n} \times \mathrm{S}^{-}}$ ${ }^{1}, n=4.74(3), \tau_{0}=3.0(5) \cdot 10^{-10} \mathrm{~s}$ and $U_{\text {eff }}=314(5) \mathrm{K}$ with $R^{2}=0.99987$ (Figure 2E).

The obtained effective energy barrier for the magnetization reversal $U_{\text {eff }}=314(5) \mathrm{K}$ is significantly smaller than expected from the theoretical calculations (CASSCF-RASSI; OpenMolcas 19.1147; for details see Supplemental Information including Tables S5 and S6 with the information on basis sets, spin-orbit energies and $g$-tensors of the lowest Kramers Doublets, respectively), predicting the fastest relaxation between the $5 \pm$ Kramers Doublet lying $576 \mathrm{~K}$ above the highly axial ground state (Figure 2B and Table S6). The value 314(5) $\mathrm{K}$ is therefore underestimated. Additional fittings of the Raman and Orbach processes with fixed $U_{\text {eff }}$ values corresponding to the calculated energies of the lower KDs were performed: $2 \pm$ of $224 \mathrm{~K}, 3 \pm$ of $363 \mathrm{~K}$ and $4 \pm$ of $475 \mathrm{~K}$. The best fits (Figures S8A-S8C) are characterized by the following $R^{2}$ values: 0.99702 for $U_{\text {eff } 2 \pm}=224 \mathrm{~K}, 0.99960$ for $U_{\text {eff } 3 \pm}=363 \mathrm{~K}$ and 0.99808 for $U_{\text {eff } 4 \pm}$ $=475 \mathrm{~K}$. The best agreement is clearly observed for $U_{\text {eff } 3 \pm}=363 \mathrm{~K}$, which corresponds to the energy of the third KD. This is also closest to the value obtained from the free fitting of the relaxation processes presented in Figure 2E. An attempt to describe the magnetic relaxation of $\mathrm{ErRe}_{3}$ using only the Raman-like process leads to a very poor fit as depicted in Figure S8D. Thus we conclude, that the observed Orbach relaxation for $\mathrm{ErRe}_{3}$ proceeds predominantly through the third Kramers Doublet, characterized by the estimated energy barrier $U_{\text {eff }}$ approaching $363 \mathrm{~K}$. This value is three times higher than that observed for the best trigonal ${ }^{42,50}$ or low-coordinate ${ }^{51,52} \mathrm{Er}^{\text {III }}$ molecules and is comparable to the $\mathrm{Er}^{\text {III }}$ sandwich and metallocene complexes. ${ }^{37,49,53-57}$ Interestingly, $\mathrm{ErRe}_{3}$ shows significantly slower relaxation as compared to $\left[\mathrm{Er}\left(\mathrm{N}\left(\mathrm{SiMe}_{3}\right)_{2}\right)_{3}\right]$ characterized by $U_{\text {eff }}=122 \mathrm{~K}^{50}$ and surpasses the theoretical limit of $306 \mathrm{~K}\left(212.6 \mathrm{~cm}^{-}\right.$

${ }^{1}$ ) for any trigonal planar molecule based on the theoretical analysis of a hypothetical $\mathrm{Er}^{\prime \prime \prime}\left(\mathrm{NH}_{2}\right)_{3}$

compound. ${ }^{58} \mathrm{ErRe}_{3}$ is a clear demonstration that direct bonding of transition metals to lanthanides might be one of the most promising directions towards room temperature MNMs, especially if paramagnetic donor atoms could be used.

\section{Conclusions}

The reported triangular molecule $\left[\mathrm{Er}^{\mathrm{III}}\left(\mathrm{Re}^{\mathrm{I}} \mathrm{Cp}_{2}\right)_{3}\right]$ constitutes the first molecular nanomagnet that mimics structurally the hardest commercial rare-earth magnet known $\mathrm{SmCo}_{5}$ and creates a connection between two incompatible fields: the rare-earth intermetallics and molecule-based compounds. $\mathrm{ErRe}_{3}$ is the first example of a lanthanide single molecule magnets coordinated solely by transition metals which enables 
the formulation of a new strategy towards molecular intermetallic nanomagnets, where the lanthanide the source of strong magnetic anisotropy - is directly coupled to the spins of softer transition metal ions playing the role of ligands.

\section{Methods}

\section{Preparation of $\left[\mathrm{Er}^{\prime \prime \prime}\left(\mathrm{Re}^{\prime} \mathrm{Cp}_{2}\right)_{3}\right] \cdot 0.5 \mathrm{C}_{6} \mathrm{H}_{6}\left(\mathrm{ErRe}_{3}\right)$}

All manipulations were performed in an argon-filled glovebox (Inert PureLab HE). [Cp ${ }_{2} \mathrm{ReH}$ (242 mg; 0.76 $\mathrm{mmol}$ ) was dissolved in anhydrous benzene $(3.5 \mathrm{ml})$ and added to the benzene solution $(2.5 \mathrm{ml})$ of $\left[\mathrm{Er}^{\prime \prime \prime}(\mathrm{btmsm})_{3}\right](160 \mathrm{mg} ; 0.25 \mathrm{mmol})$. The resulting orange solution was stirred using a glass rod for $5 \mathrm{~min}$ and then stored in a $20 \mathrm{ml}$ scintillation vial that was left open for $5 \mathrm{~h}$ inside the glovebox. After this time yellow-orange crystals appeared which were collected by vacuum filtration using a $1 \mu \mathrm{m}$ Teflon membrane. Yield: $70 \mathrm{mg}(0.061 \mathrm{mmol} ; 24 \%)$. The purity of the compound was checked by powder X-ray diffraction with the experimental pattern (Figure S4) matching nearly perfectly the simulated one from the SCXRD structural model obtained at $270 \mathrm{~K}$ (CCDC 2065531). IR, neat $\left(\mathrm{cm}^{-1}\right): 796 \mathrm{~s}, 808 \mathrm{~s}, 816 \mathrm{~s}, 832 \mathrm{~m}$, $850 \mathrm{~m}, 987 \mathrm{~s}, 1000 \mathrm{~s}, 1059 \mathrm{~m}, 1087 \mathrm{~s}, 1095 \mathrm{vs}, 1154 \mathrm{vw}, 1188 \mathrm{vw}, 1201 \mathrm{vw}, 1255 \mathrm{~m}, 1273 \mathrm{~m}, 1342 \mathrm{~m}, 1358 \mathrm{~m}$, 1394 s, 1419s, 1462m, 1479m, 1558s, 1657s, 2001vw, 2034vw, 2854s, 2929vs, 3036m, 3063s, 3089s, 3550b (Figure S9).

\section{Declarations}

\section{Acknowledgments}

This work was financed by the Polish National Science Centre within the Sonata Bis 6 project (2016/22/E/ST5/00055). The research was partially carried out with the equipment purchased thanks to the financial support of the European Regional Development Fund in the framework of the Smart Growth Operational Programme 2014-2020 (contract no. POIR.04.02.00-00-D001/20-00).

\section{Author contributions}

M.M. prepared the starting material $\left[\mathrm{Cp}_{2} \mathrm{ReH}\right]$, participated in the preparation of the target compound, performed and analysed the magnetic measurements and wrote the relevant fragment of the manuscript; M.B. prepared the starting material $\left[\mathrm{Er}^{\mathrm{III}}(\mathrm{btmsm})\right]$, participated in the preparation of the target compound, analysed its structure and wrote a relevant fragment of the manuscript; S.B. participated in the AC magnetic measurements and their analysis. V.V. performed and analysed the $a b$ initio calculations and wrote the relevant fragment of the manuscript. D.P. acquired funding, designed the experiments, performed the synthesis of the target compound, coordinated and supervised the research and wrote the manuscript. All authors reviewed and agreed to the final version of the paper. 
The authors declare no competing interests.

\section{Materials and correspondence}

Further information and requests for resources/materials should be directed to the corresponding author: Dawid Pinkowicz (dawid.pinkowicz@uj.edu.pl).

\section{Crystallographic data}

Crystallographic data for this paper (ErRe 3 at $100 \mathrm{~K}: \mathrm{CCDC} 2065530, \mathrm{ErRe}_{3}$ at $270 \mathrm{~K}: \mathrm{CCDC} 2065531$ and $\left[\mathrm{Cp}_{2} \mathrm{ReH}\right]$ at $100 \mathrm{~K}$ : CCDC 2027573) were deposited with the Cambridge Structural Database and can be obtained free of charge from the Cambridge Crystallographic Data Centre via www.ccdc.cam.ac.uk/data_request/cif. All other data are available from the lead contact without restriction.

\section{References}

1. Buschow, K.H.J., and Van Der Goot, A.S. (1968). Intermetallic compounds in the system samariumcobalt. Journal of the Less Common Metals 14, 323-328. 10.1016/0022-5088(68)90037-4.

2. Herbst, J.F., Croat, J.J., Pinkerton, F.E., and Yelon, W.B. (1984). Relationships between crystal structure and magnetic properties in Nd2Fe14B. Physical Review B 29, 4176-4178.

10.1103/PhysRevB.29.4176.

3. Croat, J.J., Herbst, J.F., Lee, R.W., and Pinkerton, F.E. (1984). High-energy product Nd-Fe-B permanent magnets. Applied Physics Letters 44, 148-149. 10.1063/1.94584.

4. Gutfleisch, O., Willard, M.A., Brück, E., Chen, C.H., Sankar, S.G., and Liu, J.P. (2011). Magnetic Materials and Devices for the 21st Century: Stronger, Lighter, and More Energy Efficient. Advanced Materials 23, 821-842. 10.1002/adma.201002180.

5. Gatteschi, D., Sessoli, R., and Villain, J. (2006). Molecular Nanomagnets 10.1093/acprof:oso/9780198567530.001.0001.

6. Goodwin, C.A.P., Ortu, F., Reta, D., Chilton, N.F., and Mills, D.P. (2017). Molecular magnetic hysteresis at 60 kelvin in dysprosocenium. Nature 548, 439-442. 10.1038/nature23447.

7. Guo, F.-S., Day, B.M., Chen, Y.-C., Tong, M.-L., Mansikkamäki, A., and Layfield, R.A. (2018). Magnetic hysteresis up to 80 kelvin in a dysprosium metallocene single-molecule magnet. Science 362, 14001403. doi:10.1126/science.aav0652.

8. Gould, C.A., McClain, K.R., Yu, J.M., Groshens, T.J., Furche, F., Harvey, B.G., and Long, J.R. (2019).

Synthesis and Magnetism of Neutral, Linear Metallocene Complexes of Terbium(II) and Dysprosium(II). Journal of the American Chemical Society $141,12967-12973$.

10.1021/jacs.9b05816.

9. Guo, F.-S., Day, B.M., Chen, Y.-C., Tong, M.-L., Mansikkamäki, A., and Layfield, R.A. (2017). A Dysprosium Metallocene Single-Molecule Magnet Functioning at the Axial Limit. Angewandte 
Chemie International Edition 56, 11445-11449. 10.1002/anie.201705426.

10. Randall McClain, K., Gould, C.A., Chakarawet, K., Teat, S.J., Groshens, T.J., Long, J.R., and Harvey, B.G. (2018). High-temperature magnetic blocking and magneto-structural correlations in a series of dysprosium(iii) metallocenium single-molecule magnets. Chemical Science 9, 8492-8503. $10.1039 / \mathrm{c} 8 \mathrm{sc} 03907 \mathrm{k}$.

11. Wu, S.-G., Ruan, Z.-Y., Zheng, J.-Y., Huang, G.-Z., Vieru, V., Chen, Y.-C., Ho, L.T.A., Liu, J.-L., Chibotaru, L.F., and Tong, M.-L. (2021). Rectangle-like hysteresis in a Dysprosium Metallacrown Magnet with Linear F-Dy-F Anisotropic Moiety. arXiv. arXiv:2105.09586.

12. Yan, D., Joana, C., Lorena, R., Salvador, C., José, J.B., and Alejandro, G.-A. (2021). Data mining, dashboards and statistics: a powerful framework for the chemical design of molecular nanomagnets. Research Square. 10.21203/rs.3.rs-490959/v1.

13. Liu, J.-L., Chen, Y.-C., and Tong, M.-L. (2018). Symmetry strategies for high performance lanthanidebased single-molecule magnets. Chemical Society Reviews 47, 2431-2453. 10.1039/C7CS00266A.

14. Ishikawa, N., Sugita, M., Ishikawa, T., Koshihara, S.-y., and Kaizu, Y. (2003). Lanthanide Double-Decker Complexes Functioning as Magnets at the Single-Molecular Level. Journal of the American Chemical Society $125,8694-8695.10 .1021 / j a 029629 n$.

15. Rinehart, J.D., and Long, J.R. (2011). Exploiting single-ion anisotropy in the design of f-element single-molecule magnets. Chemical Science 2, 2078-2085. 10.1039/C1SC00513H.

16. Reta, D., Kragskow, J.G.C., and Chilton, N.F. (2021). Ab Initio Prediction of High-Temperature Magnetic Relaxation Rates in Single-Molecule Magnets. Journal of the American Chemical Society $143,5943-$ 5950. 10.1021/jacs.1c01410.

17. Briganti, M., Santanni, F., Tesi, L., Totti, F., Sessoli, R., and Lunghi, A. (2021). A Complete Ab Initio View of Orbach and Raman Spin-Lattice Relaxation in a Dysprosium Coordination Compound. Journal of the American Chemical Society 143, 13633-13645. 10.1021/jacs.1c05068.

18. Jackson, C.E., Moseley, I.P., Martinez, R., Sung, S., and Zadrozny, J.M. (2021). A reaction-coordinate perspective of magnetic relaxation. Chemical Society Reviews 50, 6684-6699.

10.1039/D1CS00001B.

19. Harriman, K.L.M., and Murugesu, M. (2016). An Organolanthanide Building Block Approach to SingleMolecule Magnets. Accounts of Chemical Research 49, 1158-1167.

10.1021/acs.accounts.6b00100.

20. Wu, S.-G., Ruan, Z.-Y., Huang, G.-Z., Zheng, J.-Y., Vieru, V., Taran, G., Wang, J., Chen, Y.-C., Liu, J.-L., Ho, L.T.A., et al. (2021). Field-induced oscillation of magnetization blocking barrier in a holmium metallacrown single-molecule magnet. Chem 7, 982-992. 10.1016/j.chempr.2020.12.022.

21. Evans, P., Reta, D., Whitehead, G.F.S., Chilton, N.F., and Mills, D.P. (2019). Bis-Monophospholyl Dysprosium Cation Showing Magnetic Hysteresis at $48 \mathrm{~K}$. Journal of the American Chemical Society 141, 19935-19940. 10.1021/jacs.9b11515.

22. Durrant, J.P., Tang, J., Mansikkamäki, A., and Layfield, R.A. (2020). Enhanced single-molecule magnetism in dysprosium complexes of a pristine cyclobutadienyl ligand. Chemical 
Communications 56, 4708-4711. 10.1039/d0cc01722a.

23. Milios, C.J., Vinslava, A., Wernsdorfer, W., Moggach, S., Parsons, S., Perlepes, S.P., Christou, G., and Brechin, E.K. (2007). A Record Anisotropy Barrier for a Single-Molecule Magnet. Journal of the American Chemical Society 129, 2754-2755. 10.1021/ja068961m.

24. Qian, K., Huang, X.-C., Zhou, C., You, X.-Z., Wang, X.-Y., and Dunbar, K.R. (2013). A Single-Molecule Magnet Based on Heptacyanomolybdate with the Highest Energy Barrier for a Cyanide Compound. Journal of the American Chemical Society 135, 13302-13305. 10.1021/ja4067833.

25. Lis, T. (1980). Preparation, structure, and magnetic properties of a dodecanuclear mixed-valence manganese carboxylate. Acta Crystallographica Section B 36, 2042-2046.

10.1107/S0567740880007893.

26. Sessoli, R., Tsai, H.L., Schake, A.R., Wang, S., Vincent, J.B., Folting, K., Gatteschi, D., Christou, G., and Hendrickson, D.N. (1993). High-spin molecules: [Mn12012(O2CR)16(H2O)4]. Journal of the American Chemical Society 115, 1804-1816. 10.1021/ja00058a027.

27. Sessoli, R., Gatteschi, D., Caneschi, A., and Novak, M.A. (1993). Magnetic bistability in a metal-ion cluster. Nature 365, 141-143. 10.1038/365141a0.

28. He, M., Guo, F.-S., Tang, J., Mansikkamäki, A., and Layfield, R.A. (2020). Fulvalene as a platform for the synthesis of a dimetallic dysprosocenium single-molecule magnet. Chemical Science 11, 57455752. 10.1039/d0sc02033h.

29. He, M., Guo, F.-S., Tang, J., Mansikkamäki, A., and Layfield, R.A. (2021). Synthesis and singlemolecule magnet properties of a trimetallic dysprosium metallocene cation. Chemical Communications 57, 6396-6399. 10.1039/d1cc02139g.

30. Evans, P., Reta, D., Goodwin, C.A.P., Ortu, F., Chilton, N.F., and Mills, D.P. (2020). A doubledysprosocenium single-molecule magnet bound together with neutral ligands. Chemical Communications 56, 5677-5680. 10.1039/c9cc08945d.

31. Liu, J., Li, J., Xu, Z., Zhou, X., Xue, Q., Wu, T., Zhong, M., Li, R., Sun, R., Shen, Z., et al. (2021). Onsurface preparation of coordinated lanthanide-transition-metal clusters. Nature Communications 12 , 1619. 10.1038/s41467-021-21911-z.

32. Butovskii, M.V., Döring, C., Bezugly, V., Wagner, F.R., Grin, Y., and Kempe, R. (2010). Molecules containing rare-earth atoms solely bonded by transition metals. Nature Chemistry 2, 741-744. 10.1038/nchem.718.

33. Shi, K., Douair, I., Feng, G., Wang, P., Zhao, Y., Maron, L., and Zhu, C. (2021). Heterometallic Clusters with Multiple Rare Earth Metal-Transition Metal Bonding. Journal of the American Chemical Society 143, 5998-6005. 10.1021/jacs.1c01771.

34. Butovskii, M.V., Tok, O.L., Wagner, F.R., and Kempe, R. (2008). Bismetallocenes: LanthanoidTransition-Metal Bonds through Alkane Elimination. Angewandte Chemie International Edition 47, 6469-6472. 10.1002/anie.200800407.

35. Swain, A., Sen, A., and Rajaraman, G. (2021). Are lanthanide-transition metal direct bonds a route to achieving new generation $\{3 d-4 f\}$ SMMs? Dalton Transactions 50, 16099-16109. 
$10.1039 / \mathrm{d} 1 \mathrm{dt} 02256 \mathrm{c}$.

36. Gould, C.A., McClain, K.R., Reta, D., Kragskow, J.G.C., Marchiori, D.A., Lachman, E., Choi, E.-S., Analytis, J.G., Britt, R.D., Chilton, N.F., et al. (2022). Ultrahard magnetism from mixed-valence dilanthanide complexes with metal-metal bonding. Science.

37. Le Roy, J.J., Ungur, L., Korobkov, I., Chibotaru, L.F., and Murugesu, M. (2014). Coupling Strategies to Enhance Single-Molecule Magnet Properties of Erbium-Cyclooctatetraenyl Complexes. Journal of the American Chemical Society 136, 8003-8010. 10.1021/ja5022552.

38. Burns, C.P., Yang, X., Wofford, J.D., Bhuvanesh, N.S., Hall, M.B., and Nippe, M. (2018). Structure and Magnetization Dynamics of Dy-Fe and Dy-Ru Bonded Complexes. Angewandte Chemie International Edition 57, 8144-8148. 10.1002/anie.201803761.

39. Münzfeld, L., Sun, X., Schlittenhardt, S., Schoo, C., Hauser, A., Gillhuber, S., Weigend, F., Ruben, M., and Roesky, P.W. (2022). Introduction of plumbole to f-element chemistry. Chemical Science. 10.1039/D1SC03805B.

40. Zhang, P., Benner, F., Chilton, N.F., and Demir, S. (2021). Organometallic lanthanide bismuth cluster single-molecule magnets. Chem. 10.1016/j.chempr.2021.11.007.

41. Avent, A.G., Caro, C.F., Hitchcock, P.B., Lappert, M.F., Li, Z., and Wei, X.-H. (2004). Synthetic and structural experiments on yttrium, cerium and magnesium trimethylsilylmethyls and their reaction products with nitriles; with a note on two cerium $\beta$-diketiminates. Dalton Transactions, 1567-1577. $10.1039 / B 316695 \mathrm{~N}$.

42. Zhang, H., Nakanishi, R., Katoh, K., Breedlove, B.K., Kitagawa, Y., and Yamashita, M. (2018). Low coordinated mononuclear erbium(iii) single-molecule magnets with C3v symmetry: a method for altering single-molecule magnet properties by incorporating hard and soft donors. Dalton Transactions 47, 302-305. 10.1039/C7DT04053A.

43. Green, M.L.H., Pratt, L., and Wilkinson, G. (1958). 795. Biscyclopentadienylrhenium hydride. Journal of the Chemical Society (Resumed), 3916-3922. 10.1039/JR9580003916.

44. Apostolidis, C., Kanellakopulos, B., Maier, R., Rebizant, J., and Ziegler, M.L. (1991).

Bis(cyclopentadienyl)rhenium(III)chlorid: Kristallstruktur, Eigenschaften und Reaktivität; Darstellung und Charakterisierung von Cp3Re und Cp2ReH. Journal of Organometallic Chemistry 409, 243-254. 10.1016/0022-328X(91)86150-0.

45. Paciello, R.A., Kiprof, P., Herdtweck, E., and Herrmann, W.A. (1989). Synthesis and structural characterization of a mixed-ring rhenocene hydride complex, (.eta.5-cyclopentadienyl) (.eta.5pentamethylcyclopentadienyl)hydridorhenium. Inorganic Chemistry 28, 2890-2893.

10.1021/ic00313a037.

46. Bandy, J.A., Cloke, F.G.N., Copper, G., Day, J.P., Girling, R.B., Graham, R.G., Green, J.C., Grinter, R., and Perutz, R.N. (1988). Decamethylrhenocene, (.eta.5-C5Me5)2Re. Journal of the American Chemical Society 110, 5039-5050. 10.1021/ja00223a023.

47. Aquilante, F., Autschbach, J., Baiardi, A., Battaglia, S., Borin, V.A., Chibotaru, L.F., Conti, I., Vico, L.D., Delcey, M., Galván, I.F., et al. (2020). Modern quantum chemistry with [Open]Molcas. The Journal of 
Chemical Physics 152, 214117. 10.1063/5.0004835.

48. Chibotaru, L.F., and Ungur, L. (2012). Ab initio calculation of anisotropic magnetic properties of complexes. I. Unique definition of pseudospin Hamiltonians and their derivation. The Journal of Chemical Physics 137, 064112. 10.1063/1.4739763.

49. Chen, S.-M., Xiong, J., Zhang, Y.-Q., Yuan, Q., Wang, B.-W., and Gao, S. (2018). A soft phosphorus atom to "harden" an erbium(iii) single-ion magnet. Chemical Science 9, 7540-7545. 10.1039/C8SC01626G.

50. Zhang, P., Zhang, L., Wang, C., Xue, S., Lin, S.-Y., and Tang, J. (2014). Equatorially Coordinated Lanthanide Single Ion Magnets. Journal of the American Chemical Society 136, 4484-4487. 10.1021/ja500793x.

51. Brzozowska, M., Handzlik, G., Kurpiewska, K., Zychowicz, M., and Pinkowicz, D. (2021). Pseudotetrahedral vs. pseudo-octahedral Erlll single molecule magnets and the disruptive role of coordinated TEMPO radical. Inorganic Chemistry Frontiers 8, 2817-2828. 10.1039/D1QI00262G.

52. Brown, A.J., Pinkowicz, D., Saber, M.R., and Dunbar, K.R. (2015). A Trigonal-Pyramidal Erbium(III) Single-Molecule Magnet. Angewandte Chemie International Edition 54, 5864-5868. 10.1002/anie.201411190.

53. Münzfeld, L., Schoo, C., Bestgen, S., Moreno-Pineda, E., Köppe, R., Ruben, M., and Roesky, P.W. (2019). Synthesis, structures and magnetic properties of [(n9-C9H9) Ln(n8-C8H8)] super sandwich complexes. Nature Communications 10, 3135. 10.1038/s41467-019-10976-6.

54. Jiang, S.-D., Wang, B.-W., Sun, H.-L., Wang, Z.-M., and Gao, S. (2011). An Organometallic Single-lon Magnet. Journal of the American Chemical Society 133, 4730-4733. 10.1021/ja200198v.

55. Meihaus, K.R., and Long, J.R. (2013). Magnetic Blocking at $10 \mathrm{~K}$ and a Dipolar-Mediated Avalanche in Salts of the Bis(n8-cyclooctatetraenide) Complex [Er(COT)2]-. Journal of the American Chemical Society $135,17952-17957.10 .1021 / j a 4094814$.

56. Le Roy, J.J., Korobkov, I., and Murugesu, M. (2014). A sandwich complex with axial symmetry for harnessing the anisotropy in a prolate erbium(iii) ion. Chemical Communications 50, 1602-1604. 10.1039/C3CC48557A.

57. Meng, Y.-S., Wang, C.-H., Zhang, Y.-Q., Leng, X.-B., Wang, B.-W., Chen, Y.-F., and Gao, S. (2016). (Boratabenzene)(cyclooctatetraenyl) lanthanide complexes: a new type of organometallic single-ion magnet. Inorganic Chemistry Frontiers 3, 828-835. 10.1039/C6QI00028B.

58. Lu, F., Ding, M.-M., Li, J.-X., Wang, B.-L., and Zhang, Y.-Q. (2020). Why lanthanide Erlll SIMs cannot possess huge energy barriers: a theoretical investigation. Dalton Transactions 49, 14576-14583. 10.1039/D0DT02868A.

\section{Supplementary Information}

Additional experimental and methods details as well as supplementary Figures and Tables can be found in the supplementary information. Below is the complete list of items that can be found in the relevant 
file:

Description of the experimental and computational details including general synthetic considerations, details of single crystal $\mathrm{X}$-ray diffraction, details of powder $\mathrm{X}$-ray diffraction, details of infrared spectroscopy, description of magnetic measurements and details of $a b$ initio calculation.

Table S1. Selected crystallographic parameters for $\mathrm{ErRe}_{3}$ at 100 and $270 \mathrm{~K}$ and the starting material $\left[\mathrm{Cp}_{2} \mathrm{Re}{ }^{\mathrm{Ill}} \mathrm{H}\right]$ at $100 \mathrm{~K}$.

Figure S1. Structural diagrams showing the asymmetric units (ASUs) of the starting material $\left[\mathrm{Cp}_{2} \mathrm{Re}^{\mathrm{Ill} H} \mathrm{H}\right]$ (A) and the target compound $\mathrm{ErRe}_{3}(\mathrm{~B})$. The red numbers indicate the distances $(\AA)$ between the Re atoms and the centroids of the cyclopentadienyl rings. C - grey, $\mathrm{H}$ - light grey, $\mathrm{Re}$ - blue, $\mathrm{Er}$ - green, centroids white; ellipsoids at the $40 \%$ probability level for $A$ and $30 \%$ for $B$.

Figure S2. Structural diagram of $\mathrm{ErRe}_{3}$ as viewed along the $c$ crystallographic direction showing the hexagonal packing pattern of the $\left[\mathrm{Er}^{\mathrm{II}}\left(\mathrm{Re}^{\prime} \mathrm{Cp}_{2}\right)_{3}\right]$ molecules highlighted by red dotted hexagons. This type of packing leads to the formation of channels along the $c$ axis filled with benzene molecules (crystallization solvent). Cyclopentadienyl ligands and benzene molecules are represented by black sticks and $\mathrm{H}$-atoms are omitted for clarity.

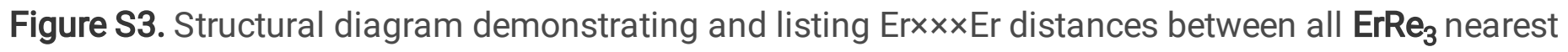
neighbours. The shortest distance is 7.6318(6) $\AA$ along the $c$ crystallographic direction.

Figure S4. Experimental (red line) and simulated (black line) powder X-ray diffraction experiments for $\mathrm{ErRe}_{3}$. The simulated pattern is calculated based on the $270 \mathrm{~K}$ single crystal X-ray diffraction structural model and includes the contribution of the $\mathrm{Cu} \mathrm{Kb}$ which is observed in the experimental pattern.

Figure S5. Temperature dependence of the molar magnetic susceptibility and temperature product $\chi T(T)$ for $\mathrm{ErRe}_{3}$ recorded at $\mu_{0} \mathrm{H}=0.1 \mathrm{~T}$ (black points). The solid red line presents the $\chi T(T)$ obtained from the ab initio calculations (see text for details). The observed anomaly below $20 \mathrm{~K}$ is caused by the magnetization blocking and the ferromagnetic interactions between the neighbouring $\mathrm{ErRe}_{3}$ molecules.

Table S2. Results of the generalized Debye model fitting of the frequency dependence of the AC magnetic susceptibility $\chi^{\prime}$ and $\chi^{\prime \prime}$ for $\mathrm{ErRe}_{3}$ recorded at zero magnetic field in the $5.5-27 \mathrm{~K}$ range presented in Figure $2 \mathrm{C}$ (main text).

Figure S6. Frequency dependence of the AC magnetic susceptibility $\chi$ and $\chi^{\prime \prime}$ for $\mathbf{E r R e}_{3}$ recorded at $H_{\mathrm{DC}}=$ $0.15 \mathrm{~T}$ in the $5.5-27 \mathrm{~K}$ range using Quantum Design MPMS3 and PPMS instruments. Solid lines are the best fits to the generalized Debye model. The relevant fitting parameters can be found in Table S3 below.

Table S3. Results of the generalized Debye model fitting of the frequency dependence of the AC magnetic susceptibility $\chi^{\prime}$ and $\chi^{\prime \prime}$ for $\mathrm{ErRe}_{3}$ recorded at $H_{\mathrm{DC}}=0.15 \mathrm{~T}$ in the $5.5-27 \mathrm{~K}$ range presented in Figure S6. 
Figure S7. Frequency dependence of the AC magnetic susceptibility $\chi$ and $\chi^{\prime \prime}$ for $\mathrm{ErRe}_{3}$ recorded at $T=7 \mathrm{~K}$ in the $0.01-2$ T range using Quantum Design MPMS3 and PPMS instruments. Solid lines are the best fits to the generalized Debye model. The relevant fitting parameters can be found in Table S4 below.

Table S4. Results of the generalized Debye model fitting of the frequency dependence of the AC magnetic susceptibility $\chi$ and $\chi^{\prime \prime}$ for $\mathrm{ErRe}_{3}$ recorded at $T=7 \mathrm{~K}$ in the $0.01-2 \mathrm{~T}$ range presented in Figure $\mathrm{S} 6$.

Table S5. The employed basis sets for ab initio calculations.

Table S6. Spin-orbit energies $\left(\mathrm{cm}^{-1}\right)$ and the $g$-tensors of the four lowest in energy Kramers doublets.

Figure S8. Temperature dependence of the magnetic relaxation rate $\tau^{-1}(T)$ for $\mathrm{ErRe}_{3}$ under applied $0.15 \mathrm{~T}$ DC magnetic field (circles). Solid lines represent the best fits assuming Raman-like and Orbach relaxation processes with $C, \mathrm{n}, \tau_{0}$ as free parameters and $U_{\text {eff }}$ fixed at $224 \mathrm{~K}(\mathrm{~A}), 363 \mathrm{~K}(\mathrm{~B}), 475 \mathrm{~K}$ (C) or Raman-like relaxation process only (D). Fitting presented in $B$ shows highest $R^{2}$ and is assumed to provide the most accurate value of the energy barrier for magnetization reversal. Fitting assuming Raman-like relaxation only (D) shows the lowest $\mathrm{R}^{2}$ which sanctions the need for including the Orbach mechanism.

Figure S9. IR spectra of crushed crystals of $\mathrm{ErRe}_{3}$ (red solid line) with the overlaid IR spectrum of $\mathbf{S m R e}_{3}$ recorded as $\mathrm{KBr}$ pellet (black solid line) reproduced from ref. S13 in the $675-4000 \mathrm{~cm}^{-1}$ range (the IR spectrum from Fig. S6 from the Supplementary Information of ref. S13 was traced using CorelDRAW 2019 software). Both spectra are very similar. Weak Re-H stretching modes at 2001 and $2034 \mathrm{~cm}^{-1}$ observed for $\mathrm{ErRe}_{3}$ are due to the slight decomposition of this extremely sensitive compound. Note, that these stretches are also present in the IR spectrum of $\mathrm{SmRe}_{3}$, but are largely obstructed by a significant background reaching $40 \%$ transmittance at $2000 \mathrm{~cm}^{-1}$ and nearly $15 \%$ transmittance at $4000 \mathrm{~cm}^{-1}$.

\section{List of references in the supplemental information}

\section{Figures}


A

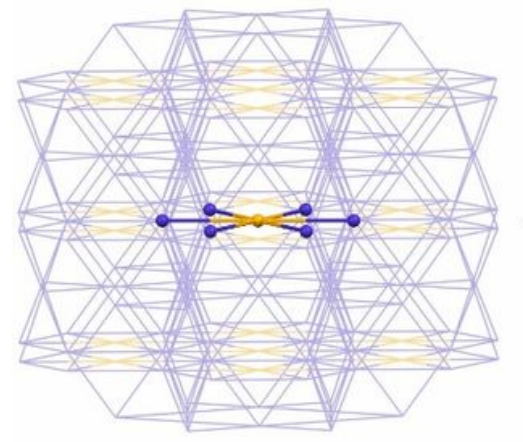

B

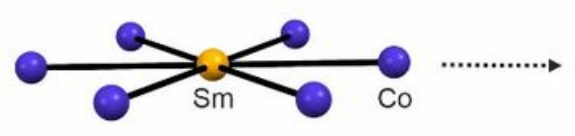

C

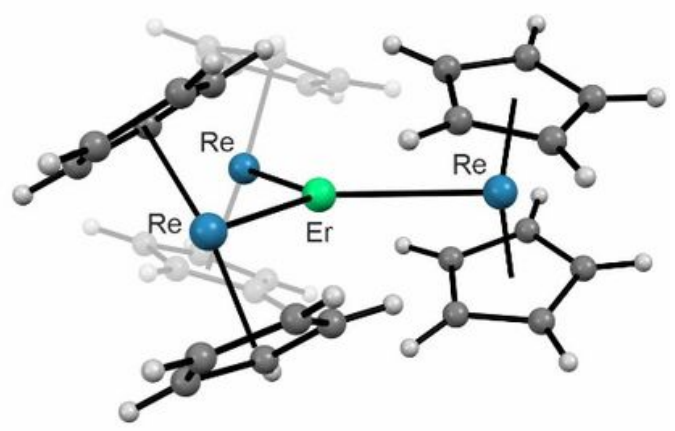

D

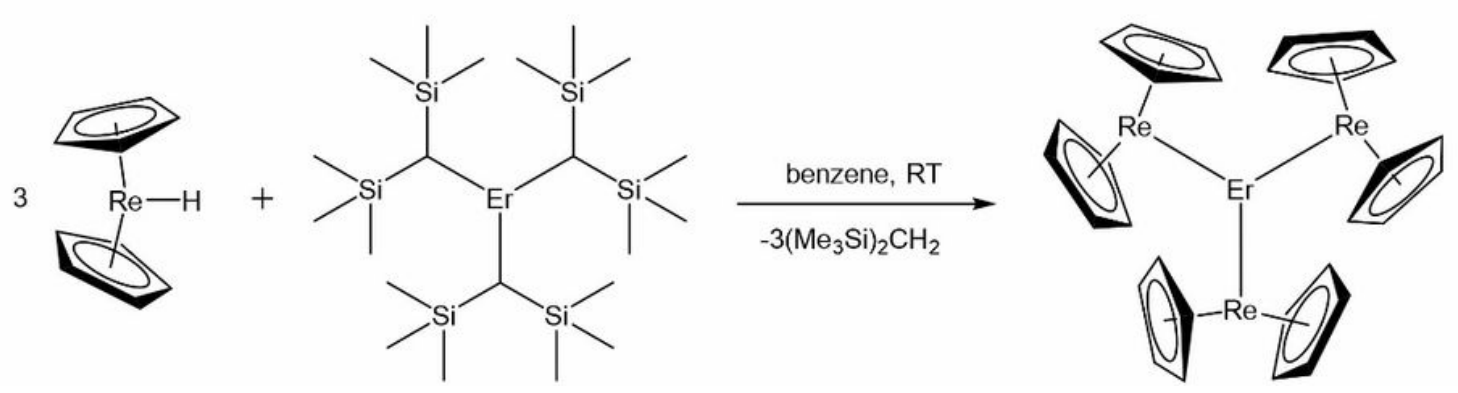

Figure 1

The synthetic strategy towards $\mathrm{ErRe}_{3}$ and its structure.

Graphical representation of the structural design transfer from the intermetallic magnet $\mathrm{SmCo}_{5}(\mathrm{~A}$ and $\mathrm{B})$ to the molecular nanomagnet $\left[\mathrm{Er}^{\prime \prime \prime}\left(\mathrm{Re}^{\mathrm{l}} \mathrm{Cp}_{2}\right)_{3}\right](\mathrm{C})$. The hexagonal planar $\mathrm{SmCo}_{6}$ coordination with unsupported coordination bonds between the center of the rare earth and six transition metals in $\mathrm{SmCo}_{5}$ $\left(A\right.$ and $B$ ) is mimicked by the trigonal planar coordination in $\operatorname{ErRe}_{3}(C)$. All three panels $A-C$ are based on single-crystal structural models of $\mathrm{SmCo}_{5}{ }^{1}$ and $\mathrm{ErRe}_{3}$. Sm-Co bonds in $\mathrm{SmCo}_{5}: 2.888 \AA$; Er-Re bonds in $\mathrm{ErRe}_{3}$ : 2.9004(5), 2.9124(5), 2.9172(5) A. Panel D presents the synthesis of $\mathbf{E r R e}_{3}$ based on the work of Kempe et al. ${ }^{32}$ This approach utilizes the reaction of the weak Brønsted acid $\left[\mathrm{Cp}_{2} \mathrm{ReH}\right]$ with the strong Brønsted base btmsm ${ }^{-}$in $\left[\mathrm{Er}^{\prime \prime \prime}(\mathrm{btmsm})_{3}\right]$ resulting in $\left(\mathrm{Me}_{3} \mathrm{Si}\right)_{2} \mathrm{CH}_{2}$ "elimination" and the formation of $\left[\mathrm{Er}^{\mathrm{III}}\left(\operatorname{Re}^{\mathrm{l}} \mathrm{Cp}_{2}\right)_{3}\right]$. 
A

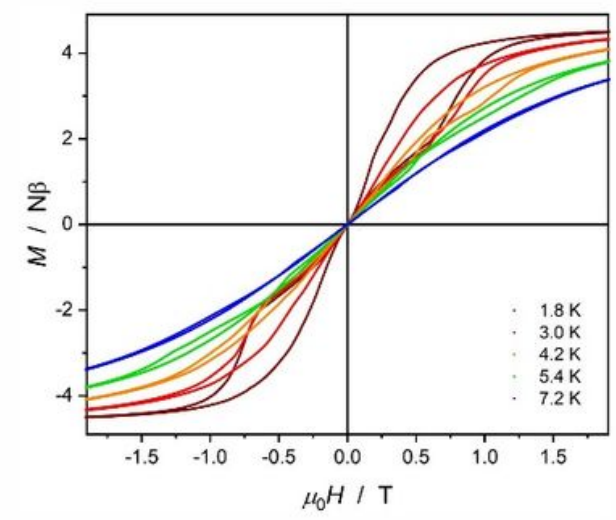

B

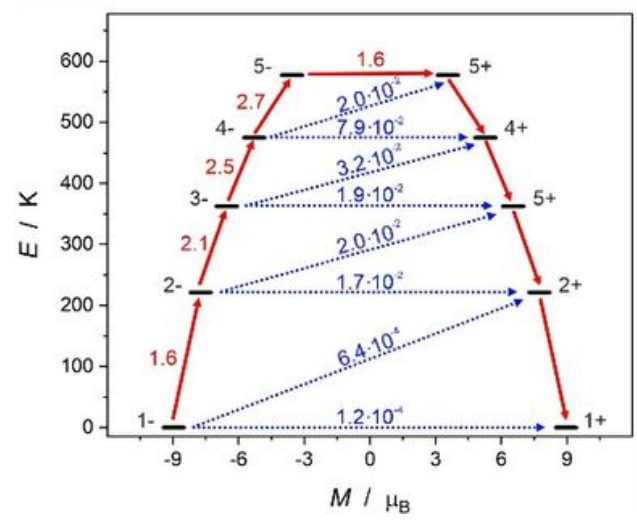

C

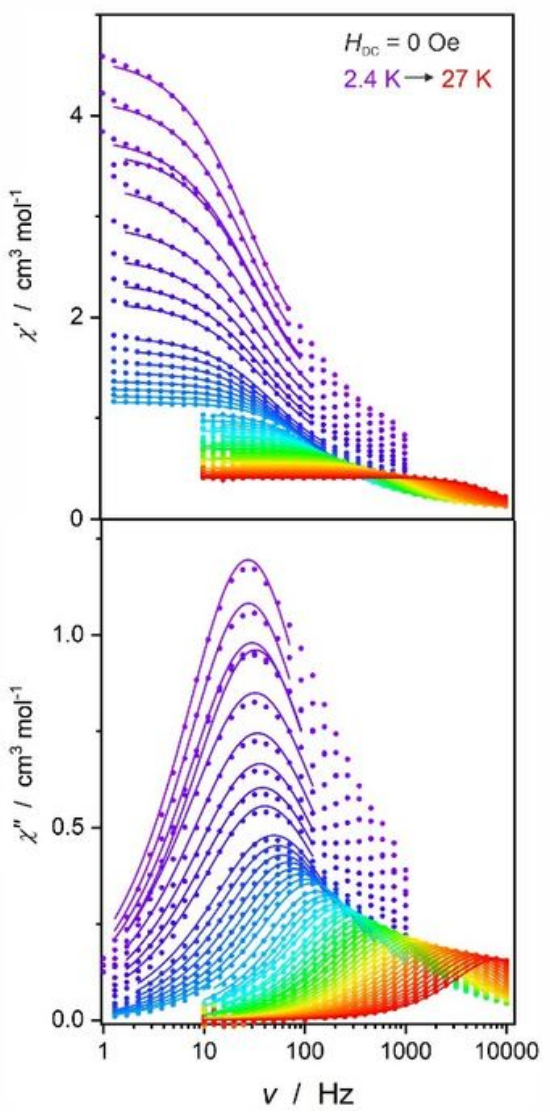

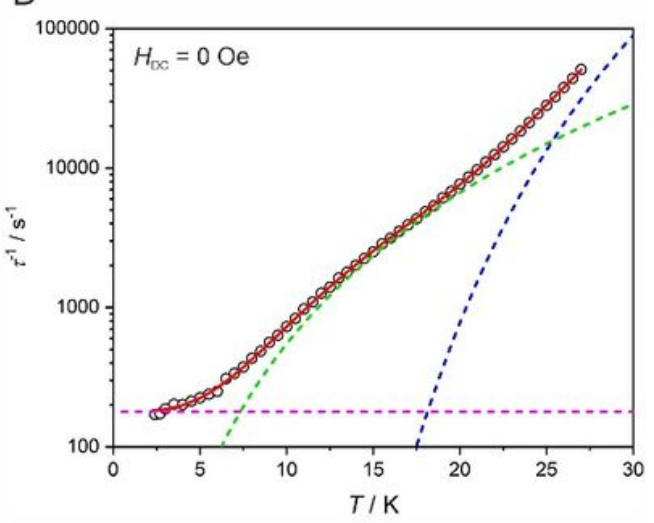

E

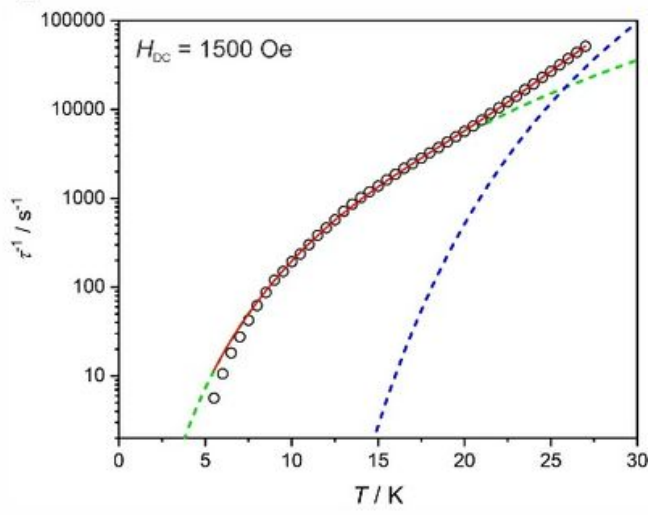

Figure 2

\section{Magnetic properties of $\mathrm{ErRe}_{3}$.}

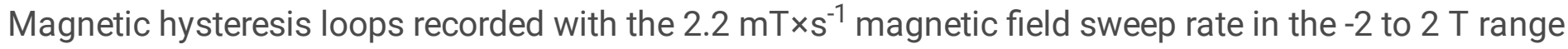
(A). Energy of the calculated Kramers Doublets (KDs) arising from the splitting of the ${ }^{4} \mathrm{I}_{15 / 2}$ multiplet of $\mathrm{Er}^{\mathrm{Ill}}$ in $\mathrm{ErRe}_{3}$ with the most probable relaxation pathway represented by the red arrows (B). AC magnetic susceptibility recorded at zero magnetic field in the $2.4-27 \mathrm{~K}$ range, demonstrating the slow magnetization dynamics of $\mathrm{ErRe}_{3}$, solid lines are the best fits to the generalized Debye model with parameters presented in Table S2 (C). Temperature dependence of the magnetization relaxation rate $t$ ${ }^{-1}(T)$ at zero (D) and $0.15 \mathrm{mT}(\mathrm{E})$ magnetic field obtained from the generalized Debye fitting of the respective AC magnetic susceptibility measurements (circles - experimental points, red line - best fits using Eq. 1 (D) and Eq. 2 (E), blue dashed line - Orbach relaxation, green dashed line - Raman relaxation, magenta dashed line - QTM relaxation).

\section{Supplementary Files}

This is a list of supplementary files associated with this preprint. Click to download.

- floatimage1.jpeg 
- SIfinal.docx

- Cp2ReH.cif

- checkcifCp2ReH.pdf

- ErRe3X270K.cif

- checkcifErRe3X270K.pdf

- ErRe3X100K.cif

- checkcifErRe3X100K.pdf 